\title{
CORRECTION
}

Check for updates

Cite this: Phys. Chem. Chem. Phys. 2021, 23, 15386

\section{Correction: A first-principles study of the stability, electronic structure, and optical properties of halide double perovskite $\mathrm{Rb}_{2} \mathrm{Sn}_{1-x} \mathrm{Te}_{x} \mathrm{I}_{6}$ for solar cell applications}

\author{
Muhammad Faizan, (D) *a Jiahao Xie, (D) ${ }^{b}$ Ghulam Murtaza, ${ }^{c}$ \\ Carlos Echeverría-Arrondo, ${ }^{d}$ Thamraa Alshahrani, ${ }^{* e}$ Kailash Chandra Bhamu, \\ Amel Laref, ${ }^{9}$ Iván Mora-Seró (DD ${ }^{* d}$ and Shah Haidar Khan ${ }^{* a}$
}

DOI: $10.1039 / \mathrm{d} 1 \mathrm{cp} 90137 \mathrm{k}$

Correction for 'A first-principles study of the stability, electronic structure, and optical properties of halide double perovskite $\mathrm{Rb}_{2} \mathrm{Sn}_{1-x} \mathrm{Te}_{x} \mathrm{I}_{6}$ for solar cell applications' by Muhammad Faizan et al.,

rsc.li/pccp Phys. Chem. Chem. Phys., 2021, 23, 4646-4657, DOI: 10.1039/D0CP05827K.

The published version of this manuscript included errors in the text in the last paragraph of page 4653 . The correct sentences are given below:

For $\mathrm{Rb}_{2} \mathrm{Sn}_{0.75} \mathrm{Te}_{0.25} \mathrm{I}_{6}$, the strongest absorption $\left(\sim 6.9 \times 10^{5} \mathrm{~cm}^{-1}\right)$ occurs at approximately $2.93 \mathrm{eV}$. Similarly, for $\mathrm{Rb}_{2} \mathrm{Sn}_{0.50} \mathrm{Te}_{0.50} \mathrm{I}_{6}$, the maximum absorption $\left(5.82 \times 10^{5} \mathrm{~cm}^{-1}\right)$ occurs at $\sim 3.1 \mathrm{eV}$.

The Royal Society of Chemistry apologises for these errors and any consequent inconvenience to authors and readers.

\footnotetext{
${ }^{a}$ Department of Physics, University of Peshawar, Peshawar 25120, Pakistan.E-mail: faizanstd@uop.edu.pk, shkhan@uop.edu.pk

${ }^{b}$ State Key Laboratory of Superhard Materials and School of Materials Science and Engineering, Jilin University, Changchun 130012, China

${ }^{c}$ Materials Modeling Lab, Department of Physics, Islamia College University, Peshawar 25120, Pakistan

${ }^{d}$ Institute of Advanced Materials (INAM), Universitat Jaume I, Castelló 12006, Spain. E-mail: sero@uji.es

${ }^{e}$ Department of Physics, College of Science, Princess Nourah Bint Abdulrahman University, Riyadh 11671, Saudi Arabia. E-mail: thmalshahrani@pnu.edu.sa

${ }^{f}$ School of Chemical Engineering, University of Ulsan, 93 Daehakro, Nam-Gu, Ulsan 44610, South Korea

${ }^{g}$ Department of Physics and Astronomy, College of Science, King Saud University, Riyadh 11451, Kingdom of Saudi Arabia
} 